\title{
FAK Inhibitor VS-4718
}

National Cancer Institute

\section{Source}

National Cancer Institute. FAK Inhibitor VS-4718. NCI Thesaurus. Code C107238.

An orally bioavailable focal adhesion kinase (FAK) inhibitor with potential antineoplastic activity. Upon administration, VS-4718 inhibits FAK, blocks fibronectin-stimulated FAK autophosphorylation of Tyr397, and may prevent the integrin-mediated activation of several downstream signal transduction pathways, including ERK, JNK/MAPK and PI3K/Akt. This results in the reduction of the number of cancer stem cells (CSCS) and inhibits tumor cell migration, proliferation and survival. The cytoplasmic tyrosine kinase FAK is a signal transducer for integrins and is constitutively activated in various tumor cell types; it is involved in tumor cell invasion, migration and proliferation and plays a key role in the development, function and survival of CSCs. 